\title{
Pattern of Cutaneous Immunoglobulin G Deposition in Subacute Cutaneous Lupus Erythematosus Is Reproduced by Infusing Purified Anti-Ro (SSA) Autoantibodies into Human Skin-grafted Mice
}

\author{
Lela A. Lee, ${ }^{\star \$ 5}$ Kimberley K. Gaither, ${ }^{\| \uparrow}$ Silvija N. Coulter, ${ }^{\star}$ David A. Norris, ${ }^{\star}$ and John B. Harley ${ }^{\| \uparrow \star \star}$ \\ Departments of ${ }^{*}$ Dermatology and ${ }^{\ddagger}$ Medicine, University of Colorado School of Medicine; and ${ }^{\S}$ Veterans Administration Hospital, \\ Denver, Colorado 80262; "Departments of Medicine and Microbiology, University of Oklahoma Health Sciences Center; \\ "Arthritis and Immunology Program, Oklahoma Medical Research Foundation; and **Veterans Administration Medical Center, \\ Oklahoma City, Oklahoma 73104
}

\begin{abstract}
Subacute cutaneous lupus and neonatal lupus are closely associated with the presence of anti-Ro (SSA) autoantibodies, but there is no direct evidence establishing a role for anti-Ro (SSA) in these diseases. After parenteral injection into mice, IgG from sera containing anti-Ro (SSA) will bind human skin grafted onto the mice. To determine whether the antibody binding is due to anti-Ro (SSA), affinity-purified anti-Ro (SSA) and serum depleted of anti-Ro (SSA) were prepared. After injection into human skin-grafted mice, purified anti-Ro (SSA) antibodies bound an antigen in the human skin graft, while preabsorbing anti-Ro (SSA) serum with Ro (SSA) virtually abolished binding to the human skin graft. Moreover, the pattern of Ig deposition was primarily epidermal and was identical in the human skin-grafted mice injected with purified anti-Ro (SSA) when compared with that found in five patients with subacute cutaneous lupus (four adults, one neonate). These data directly show that anti-Ro (SSA) antibodies bind to the skin, and support the hypothesis that anti-Ro (SSA) autoantibodies are involved in the disease process that produces subacute cutaneous lupus and neonatal lupus.
\end{abstract}

\section{Introduction}

The majority of patients with subacute cutaneous lupus erythematosus (SCLE) ${ }^{1}$ and with neonatal lupus erythematosus (NLE) have antibodies to the Ro (SSA) antigen $(1,2)$. In NLE, these anti-Ro (SSA) autoantibodies are maternal in origin and cross the placenta. Their presence in the affected neonate's serum correlates well with disease activity in the skin. The disease activity generally resolves as the antibody titer decreases, both disappearing by about 6 mo of age. These observations have led to the proposal that anti-Ro (SSA) autoantibodies may play an important, and possibly direct, role in the disease process in SCLE and cutaneous neonatal lupus.

Address correspondence to Dr. Lela A. Lee, Box B-153, University of Colorado School of Medicine, 4200 East Ninth Avenue, Denver, CO 80262.

Received for publication 27 May 1988 and in revised form 23 November 1988.

1. Abbreviations used in this paper: ARA, American Rheumatism Association; DLE, discoid lupus erythematosus; NLE, neonatal lupus erythematosus; SCID, severe combined immunodeficiency; SCLE, subacute cutaneous lupus erythematosus; SLE, systemic lupus erythematosus.

The Journal of Clinical Investigation, Inc.

Volume 83, May 1989, 1556-1562
We have previously reported studies in the nude mouse with grafted human skin, a model that pertains to anti-Ro (SSA)-associated skin disease in lupus (3). Grafted mice were injected parenterally with sera from patients who had anti-Ro (SSA) antibodies. The human skin grafts were then examined for the presence of human IgG. Since human $\mathrm{IgG}$ was found in the skin grafts when anti-Ro (SSA) but not control serum was injected, it seemed likely that anti-Ro (SSA) antibodies were deposited in the skin (3). Though antibody binding observed in the nude mouse model may have represented specific binding of anti-Ro (SSA) to Ro (SSA) antigen in the skin, there were two major alternate explanations. First, antibodies other than anti-Ro (SSA) may have been responsible for antibody deposition in the graft. For example, anti-La (SSB) might be considered a likely candidate since anti-La (SSB) antibodies are commonly found in sera containing anti-Ro (SSA) (4). Alternatively, other phenomena associated with anti-Ro (SSA) could be responsible, such as physical or binding properties of selected antibody as determined by idiotype. Finally, human anti-Ro (SSA) antibodies may have bound to mouse Ig present in the skin graft rather than to Ro (SSA) (or a crossreactive) antigen. Anti-Ro (SSA) antibodies have been reported to possess rheumatoid factor-like activity (5), and could potentially bind mouse IgG found in the human skin grafts.

Reagents were specifically prepared to define the cutaneous binding of anti-Ro (SSA) to human skin as well as to address these alternate explanations. Human skin grafts were prepared in mice with severe combined immunodeficiency (SCID) which synthesize virtually no mouse Ig. These mice were infused with immunoaffinity anti-Ro (SSA) or serum whose anti-Ro (SSA) activity had been largely removed by preincubation with purified Ro (SSA) antigen. Antibody binding in the animal model was compared with antibody binding seen in lesions of SCLE and NLE. The results demonstrate that anti-Ro (SSA) not only binds human skin but also binds in the human skin graft in a pattern of deposition indistinguishable from that seen in lesions of anti-Ro (SSA) donors we examined with SCLE.

\section{Methods}

Case descriptions. Patient 1 was a 33-yr-old white female. In 1980 and 1981, although asymptomatic, she delivered two successive infants with cutaneous neonatal lupus. At that time her serum had a positive antinuclear antibody titer on an HEp-2 substrate of $>256$, no detectable anti-double stranded DNA, and a Ro (SSA) precipitin titer of 32 by Ouchterlony immunodiffusion. Later samples showed an anti-Ro (SSA) titer of 128 by counterimmunoelectrophoresis and $35.8 \times 10^{6} \mathrm{U}$ of anti-Ro (SSA) in a solid phase enzyme immunoassay (6), which is $\sim 7 \mathrm{mg}$ anti-Ro (SSA)/ml serum (7). Antibodies to La (SSB) or 
$\mathrm{U}_{1}$ RNP were not detected. In 1983 she developed annular, scaly, erythematous plaques on sun-exposed skin of the arms. The clinical appearance was typical of subacute cutaneous lupus lesions. The biopsy of involved skin showed basal cell damage and a superficial mononuclear cell infiltrate, consistent with subacute cutaneous lupus. A biopsy from involved skin was also examined by immunofluorescence techniques. These lesions resolved after $\sim 2$ mo without systemic treatment and have recurred only infrequently, after sun exposure. No residual scarring or pigmentary changes were seen. She had arthralgias for $\sim 2$ mo during 1984. Otherwise, she had no evidence of systemic lupus erythematosus (SLE), and did not satisfy the revised diagnostic criteria of the American Rheumatism Association (ARA) for this disorder (8).

Her first child, born in 1980 after an uncomplicated pregnancy, developed skin lesions of neonatal lupus at $8 \mathrm{wk}$ of age after sun exposure. The lesions appeared as annular, scaly, erythematous plaques with mild central epidermal atrophy on the face, arms, and legs. A skin biopsy processed for hematoxylin and eosin examination and immunofluorescence examination was interpreted as consistent with lupus erythematosus. These lesions resolved by $\sim 6$ mo of age. They recurred at 7 mo of age after another episode of sun exposure, but cleared up after $2 \mathrm{wk}$ and did not recur.

A second child, born in 1981, developed annular, scaly, erythematous lesions on the face at $7 \mathrm{wk}$ of age, despite careful sun protection (9). A skin biopsy processed for hematoxylin and eosin examination and immunofluorescence examination was consistent with lupus erythematosus. The lesions had resolved at the time of follow-up at $8 \mathrm{mo}$ of age.

Patient 2 had hypergammaglobulinemic purpura and satisfied the ARA revised criteria for the diagnosis of SLE. She did not have any children, nor did she have a skin rash other than purpura. The patien had a positive antinuclear antibody on an HEp-2 substrate at a titer of 120 and an anti-Ro (SSA) precipitin. She had no anti-single stranded DNA by the Farr assay (10) and no anti-double stranded DNA by Crithidia luciliae (11). In solid phase assays performed as described (6), she had $6.9 \times 10^{6} \mathrm{U}$ of anti-Ro(SSA) $(\sim 1.4 \mathrm{mg} / \mathrm{ml}$ of serum). Neither anti-La (SSB) nor anti- $\mathrm{U}_{1} \mathrm{RNP}$ was detectable in her serum.

Antigen purification. Ro (SSA) antigen was purified to homogeneity as modified from the published description (12) and used for the solid phase assays and for construction of an affinity column. Briefly, bovine spleen was homogenized in an equal volume of PBS at $\mathrm{pH} 7.2$ in the presence of $0.03 \%$ DTT and $0.004 \%$ PMSF. After removal of particulate material by centrifugation, the extract was mixed with DE-52 ion exchange column support (Whatman Laboratory Products Inc., Clifton, $\mathrm{NJ}$ ). The protein, batch eluted by $0.5 \mathrm{M} \mathrm{NaCl}$ in phosphate buffer, pH 7.2, was directly applied to an anti-Ro (SSA)-Sepharose 4B (Pharmacia Fine Chemicals, Piscataway, NJ) affinity column constructed from the total $\mathrm{IgG}$ of a carefully selected patient serum containing high titers of anti-Ro (SSA) and no other detectable autoantibodies. The bound material was eluted by a gradient of $\mathrm{MgCl}_{2}$ to 3 $\mathrm{M}$ and analyzed for contaminants by SDS-PAGE, solid phase assays, and immunodiffusion. Bovine or human IgG contaminants were absorbed when necessary with staphylococcus protein A coupled to Sepharose 4B. Only preparations homogeneous by all applied standards were used for these experiments.

Anti-Ro (SSA) purification. Purified Ro (SSA) was coupled to cyanogen bromide-activated Sepharose 4B following the manufacturer's instructions (Pharmacia Fine Chemicals). The anti-Ro (SSA) antibodies were purified or absorbed by passing serum or purified IgG (6) over the Ro (SSA) column, followed by elution with $3 \mathrm{M} \mathrm{MgCl}_{2}$. The Ig eluted was dialyzed into $0.02 \mathrm{M}$ Tris- $\mathrm{HCl}, \mathrm{pH}$ 7.2. The specific antiRo (SSA) activity of the eluted antibody or adsorbed serum was estimated and compared with whole IgG or serum using the anti-Ro (SSA) solid phase assay. $80 \%$ of the specific anti-Ro (SSA) activity was removed by absorption with the Ro (SSA) column.

Solid phase assays for anti-RNA protein activity. Purified Ro (SSA), La (SSB), or $\mathrm{U}_{1}$ RNP were used in the enzyme-linked immunosorbent assay to detect the respective autoantibodies as described (6).
Typically, $1-3 \mu \mathrm{g} / \mathrm{ml}$ of antigen was incubated in U-vinyl 96-well plates (Costar, Cambridge, MA) in a $0.05 \mathrm{M}$ carbonate buffer at $\mathrm{pH}$ 9.6. A dilution of serum or concentration of $\mathrm{IgG}$ was selected that was sufficient to partially saturate the antigen relative to standards. The anti-RNA protein antibodies were revealed by goat anti-human gamma chain conjugated to alkaline phosphatase (Sigma Chemical Co., St. Louis, MO), washed, and incubated with the para-nitrophenylphosphate substrate. The reaction was monitored at $405 \mathrm{~nm}$ using a Microelisa reader (Dynatec Laboratories Inc., Alexandria, VA). As a test of specificity, appropriate dilutions of sera were preincubated with $10 \mu \mathrm{g} / \mathrm{ml}$ of the RNA protein being tested to block antibody reactivity.

Assays of anti-Ig activity. For testing rheumatoid factor activity against human Ig, a standard Latex agglutination test (Difco Laboratories Inc., Detroit, MI) was used. A second assay for testing anti-mouse Ig activity was also applied. Total IgG purified from both sera 1 and 2 were coated on a microtiter dish at $5 \mu \mathrm{g} / \mathrm{ml}$ overnight at $4^{\circ} \mathrm{C}$. Nude mouse serum was added at a 1:100 dilution in PBS-TWEEN $(0.02 \mathrm{M}$ phosphate buffer, $0.15 \mathrm{M} \mathrm{NaCl}, 0.1 \% \mathrm{BSA}$, and $0.05 \%$ TWEEN-20, $\mathrm{pH}$ 7.4) and incubated $3 \mathrm{~h}$ at room temperature. Anti-mouse IgG conjugated to alkaline phosphatase (Sigma Chemical Co.), diluted 1:1,000 in PBS-TWEEN, was added to the plate and incubated $3 \mathrm{~h}$ at room temperature. Development with substrate proceeded as described above.

Skin grafting. Male and female BALB/c nude athymic mice (Harlan Sprague Dawley, Inc., Indianapolis, IN) and male and female SCID mice (Fox Chase Cancer Institute, Philadelphia, PA) were grafted with human skin as described by Krueger and Emam (13). The source of skin was tissue that would otherwise have been discarded after abdominoplasty or mammoplasty and was obtained in accordance with the policies of the Institutional Review Board for human investigation. The skin donors were all female and were apparently healthy. No anti-Ro (SSA) activity was detected in nude mouse serum. Grafts were allowed to heal for 1 mo before use.

Antibody injections and skin biopsies. Antisera and purified antibodies were injected into the peritoneal cavity of grafted mice. $1 \mathrm{~d}$ later the human skin grafts were removed, frozen, and stored at $-70^{\circ} \mathrm{C}$ until further use. Direct immunofluorescence for human IgG and mouse IgG was performed by a standard method (14).

Case descriptions of subacute cutaneous lupus patients. Lesional skin from five patients with SCLE was examined. Two of these patients were patient 1 , described above, and one of her children. The remaining three patients were adults, one female and two males. All patients had subacute cutaneous lupus lesions on clinical examination. Except for transient arthralgias in patient 1 , none of these patients had other symptoms and none met the ARA criteria for SLE. All patients had anti-Ro (SSA) antibodies. None had detectable anti-DNA, -Sm, -RNP, or - La (SSB) autoantibodies.

\section{Results}

When grafted nude mice and SCID mice were injected with $0.1 \mathrm{ml}$ anti-Ro (SSA) sera, human IgG antibodies could be detected in the skin grafts. The predominant finding in all grafts was a particulate deposition of $\operatorname{IgG}$ in the epidermis which on occasion obscured the epidermal-dermal junction. In most areas the epidermal staining appeared to be predominantly cytoplasmic (Fig. $1 \mathrm{~A}$ ), although some epidermal cells seemed to be outlined by the antibody deposition. Many areas had nuclear staining in addition to cytoplasmic staining (Fig. 1 $B$ ). In occasional areas there was accentuation of $\mathrm{IgG}$ deposition at the basal cell layer (Fig. $1 C$ ). Only rarely was there IgG deposition under the basement membrane zone in the absence of epidermal deposition (Fig. 1 D ). All of these patterns of staining could, and often did, occur within the same biopsy. Much less striking than the epidermal IgG deposits was occasional particulate IgG deposition in the dermis, often visible around blood vessels. 

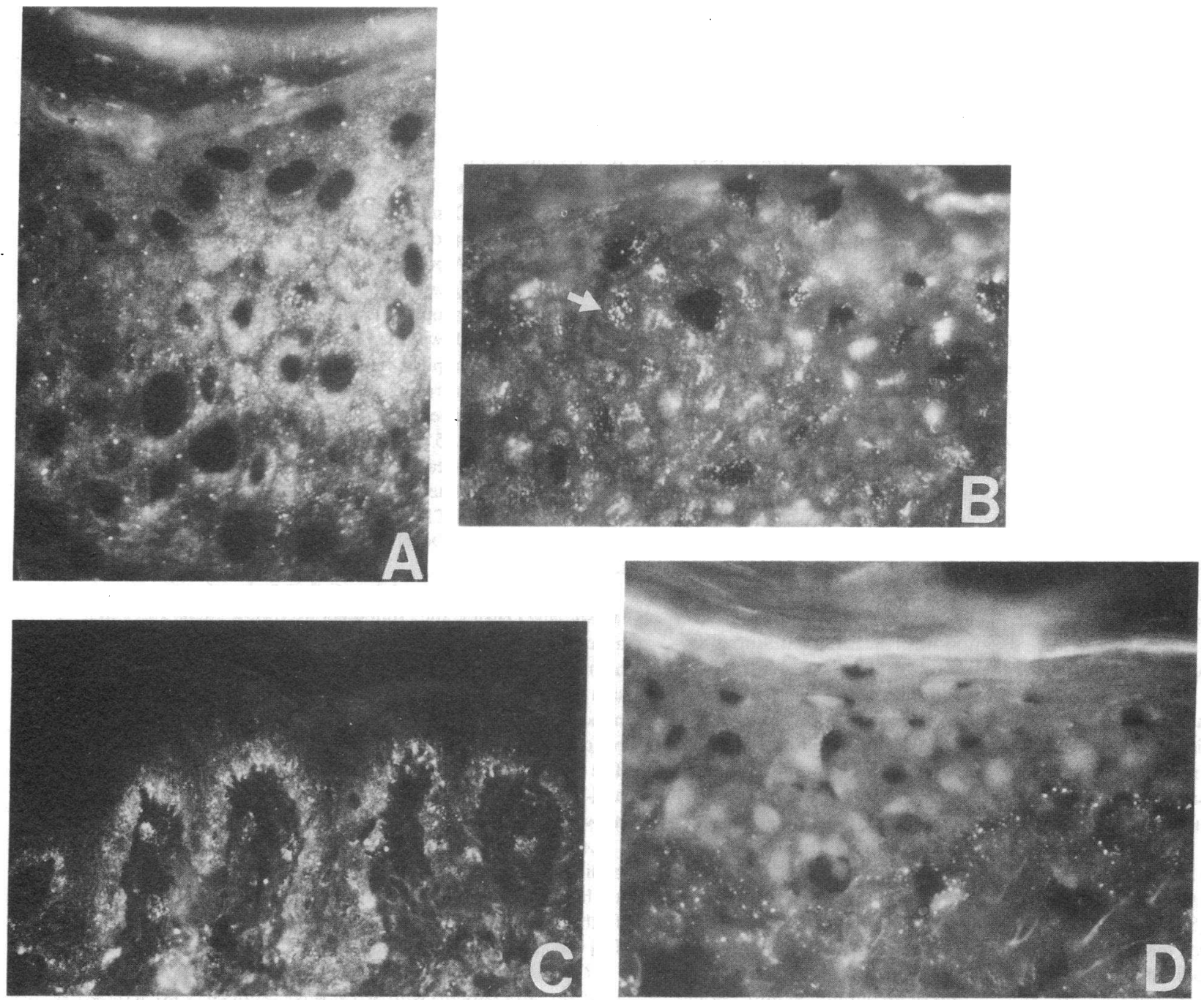

Figure 1. The spectrum of immunofluorescent findings in the animal model. Mice were grafted with human skin, then injected with anti-Ro (SSA) sera or purified anti-Ro (SSA) antibodies. Human skin grafts recovered from the mice were examined for the deposition of human IgG. Antibody-binding patterns were identical in nude and SCID mice and in animals injected with anti-Ro (SSA) serum and purified anti-Ro (SSA) antibodies. Depicted in the figure are examples of IgG antibody deposition in human skin grafts on SCID mice, as determined by a direct immunofluorescence technique. $(A)$ Particulate staining is shown throughout the epidermis. This is the most common pattern seen. (Human skin graft on SCID mouse injected with purified anti-Ro (SSA) antibodies; original magnification, $\times 630$.) $(B)$ Epidermal staining is demonstrated with accentuation of staining in nuclear areas. An arrow points to an epidermal cell nucleus. (Human skin graft on SCID mouse injected with anti-Ro serum; original magnification, $\times 630$.) $(C)$ Epidermal staining is predominantly in the basal cell layer in this photomicrograph. (Human skin graft on SCID mouse injected with anti-Ro serum; original magnification, $\times 400$.) $(D)$ Staining under the basement membrane zone is shown. (Human skin graft on SCID mouse injected with anti-Ro serum; original magnification, $\times 400$. Some of the epidermal nuclei appear bright as a result of paraphenylenediamine, which is used in the mounting medium to prolong immunofluorescence.)

The spectrum of immunofluorescent findings in the animal model parallels that which we have observed in patients with SCLE and NLE (Fig. 2). Of five patients whose lesions have been examined, all five had a particulate deposition of IgG that was predominantly epidermal. In most areas of the skin biopsies, particulate cytoplasmic staining was seen (Fig. 2 $A$ ), with or without particulate nuclear staining (Fig. $2 \mathrm{~B}$ ). Fewer areas of the biopsies showed staining predominantly in the basal layer of the epidermis (Fig. $2 C$ ). Deposits under the basement membrane zone (lupus band) were not seen in these patients. In several areas there was a minor particulate deposition of IgG in the dermis, which often appeared around blood vessels. Two of the five patients examined were patient 1 (Fig.
$2 B$ ), whose anti-Ro (SSA) autoantibodies were used in these studies, and a daughter of patient 1 (Fig. $2 C$ ), who had cutaneous neonatal lupus. (The skin biopsy from her other affected daughter was not available for review.)

Particulate epidermal staining has been frequently noted in patients with mixed connective tissue disease, but has been assumed to be an artifact (15). It was hypothesized that, during sectioning, the blade cutting through the dermis would drag serum from the dermis across the epidermis. Anti- $U_{1} R N P$ antibodies in the serum, present in high titers in mixed connective tissue disease, would then bind to the epidermis during sectioning. To address the possibility that the epidermal staining seen with anti-Ro (SSA) is an artifact of sectioning, we 

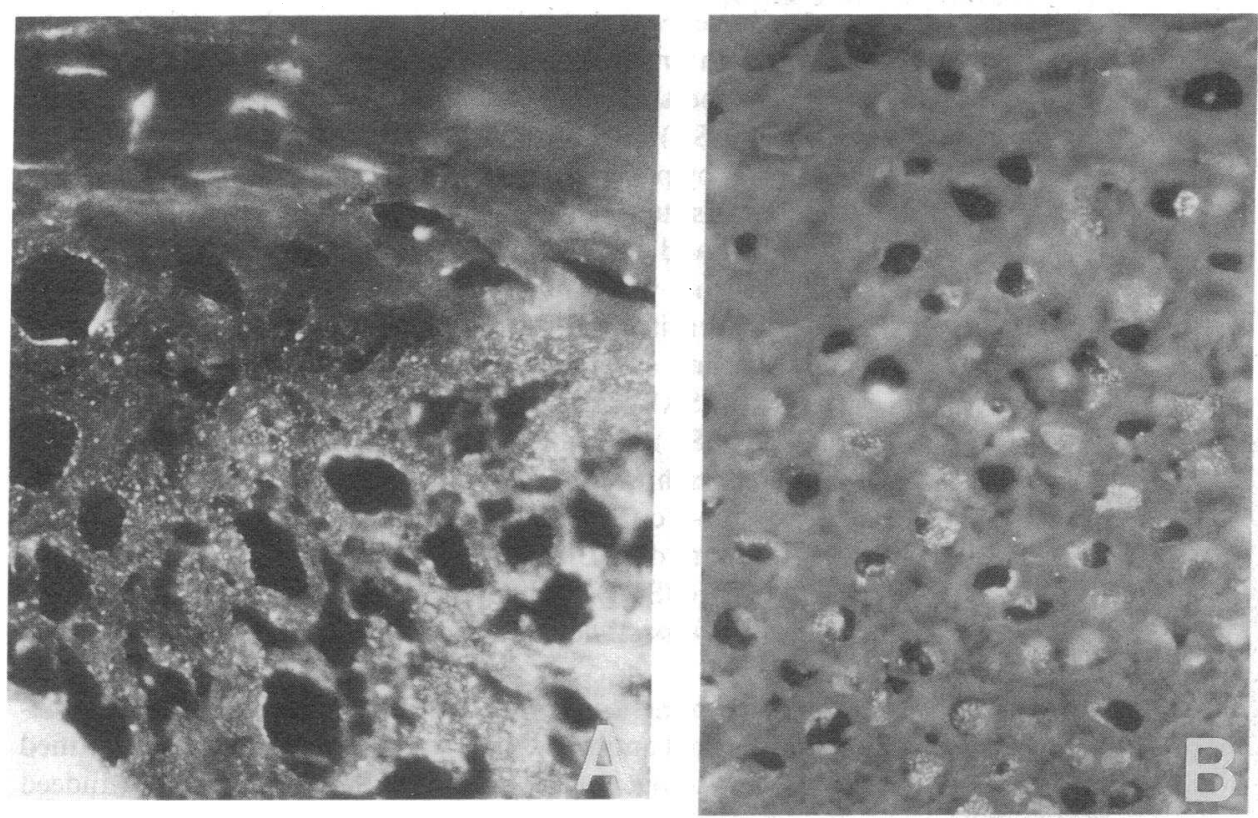

Figure 2. The spectrum of immunofluorescent findings in lesional skin from SCLE and NLE patients. Biopsies shown are examined for IgG deposition with a direct immunofluorescence technique. $(A)$ This photomicrograph of an SCLE lesion illustrates cytoplasmic epidermal staining. (Original magnification, $\times 630$.) $(B)$ This photomicrograph of an SCLE lesion illustrates epidermal nuclear staining. The biopsy is from patient 1 , whose serum and purified anti-Ro (SSA) antibodies were used for the injections shown in Fig. 1 . (Original magnification, $\times 630$.) $(C)$ This photomicrograph of an NLE skin lesion illustrates epidermal staining in the basal cell layer. This biopsy is from an offspring of patient 1 . (Original magnification, $\times 630$. The nuclear counterstain effect of paraphenylenediamine is obvious in this photomicrograph. $\mathrm{Re}-$ printed from Arthritis and Rheumatism Journal, copyright 1986 . Used by permission of the American Rheumatism Association.)

apposed a biopsy of human skin from an animal injected with anti-Ro (SSA) to a biopsy of normal human skin. The sections were cut so that the blade cut through the dermis of the grafted skin, then the graft's epidermis, the normal epidermis, and the normal dermis (Fig. $3 A$ ). If the epidermal staining we observed is an artifact of sectioning, we would expect that the cryostat blade would drag serum not only across the graft epidermis but across the normal epidermis as well. We would then see IgG deposition in the graft epidermis and normal epidermis. What we actually observed was IgG deposition in the human skin graft but not in the normal epidermis, verifying that the epidermal staining is not artifactual (Fig. $3 \mathrm{~B}$ ).

As in previous experiments, when anti-Ro (SSA) serum was injected into grafted mice, there was no detectable human IgG deposition in mouse skin (3). The reason for this lack of IgG deposition probably relates to the fact that human antiRo (SSA) antibodies frequently do not bind murine Ro (SSA) antigen (3). There was no evidence of human IgG deposition in the human skin grafts of over 20 mice who were injected with normal human serum in these and previous experiments.

As an additional test of the specificity of the IgG deposited in the human skin graft, serum from patient 2 was absorbed with the Ro (SSA) affinity column, thereby removing $80 \%$ of the anti-Ro (SSA) binding activity. When two nude mice were injected with $0.1 \mathrm{ml}$ of absorbed sera, the IgG deposition in the human skin grafts was markedly diminished (Fig. 4).

Further experiments to determine the specificity of the IgG deposited in the human skin grafts were performed using affinity-purified anti-Ro (SSA) antibodies. When $1.2 \mathrm{mg}$ of affinity-purified anti-Ro (SSA) IgG from patient 2 was injected, antibody binding was readily detectable in the human skin graft in the same pattern previously observed with whole serum (figure not shown).

Immunofluorescence examination of the human skin grafts for the deposition of mouse Ig showed mouse IgG to be present in the human skin grafted onto nude mice. To determine if anti-Ro (SSA) antibodies were binding to the mouse Ig present in the skin grafts by anti-IgG activity found in anti-Ro (SSA) sera (5), mice with SCID were studied. These mice had T and B cell deficiencies and synthesized virtually no $\mathrm{Ig}(16)$. As anticipated, no mouse IgG was detected by immunofluorescence in human skin grafts on SCID mice. Anti-Ro (SSA) injected into the grafted SCID mice produced the same immunofluorescence pattern as seen in nude mice, establishing that anti-Ro (SSA) was not binding via an interaction with mouse Ig. Of five grafted SCID mice injected with anti-Ro (SSA) 

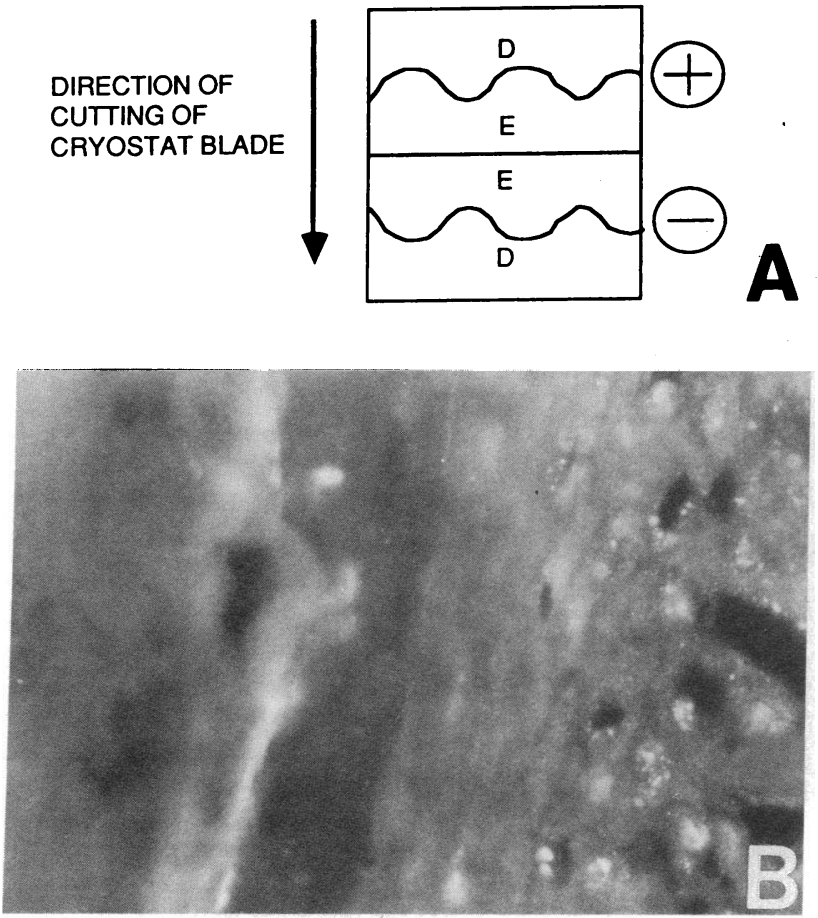

Figure 3. Demonstration that epidermal IgG staining is not an artifact of sectioning. $(A)$ A human skin graft from an animal injected with anti-Ro (SSA) was placed on a tissue block apposed to normal human skin. The skin sections were cut with the direction of the cryostat blade as shown ( $D$, dermis; $E$, epidermis). If epidermal staining in the human skin graft were due to serum being dragged across the epidermis during sectioning, then staining should be seen in the epidermis of the normal skin as well. + , Positive control, graft from an animal injected with anti-Ro; -, negative control, normal skin. (B) Direct immunofluorescence examination for human IgG in a human skin graft from an animal injected with anti-Ro (SSA), apposed to a section of normal skin. Normal skin is on the lefthand side of this photomicrograph, and skin from an animal injected with anti-Ro (SSA) is on the right. There is particulate epidermal staining in the skin graft from an animal injected with anti-Ro (SSA), but not in the normal skin. This indicates that the epidermal staining in the graft is not an artifact of tissue sectioning. (Original magnification, $\times 630$.)

serum, human IgG could be found in the skin grafts of each in the patterns as described above (see Fig. 1). An additional grafted SCID mouse that was injected with $1.4 \mathrm{mg}$ of affinitypurified anti-Ro (SSA) antibodies from serum 1 had IgG antibody deposition in the epidermis (Fig. $1 A$ ). Further, by a solid phase assay human anti-Ro (SSA) IgG did not bind mouse Ig.

\section{Discussion}

Subacute cutaneous lupus and neonatal lupus are diseases strongly associated with the presence of anti-Ro (SSA) antibodies. About $80 \%$ of SCLE patients and $95 \%$ of neonatal lupus patients have anti-Ro (SSA) antibodies $(1,2)$. Since the skin disease activity in babies with neonatal lupus coincides with the presence of anti-Ro (SSA) in the infant's serum, it has been suspected that anti-Ro (SSA) antibodies may be involved in the disease process. Ro (SSA) antigen has been demonstrated to be present in normal skin $(17,18)$ and may appear on the cell surface of cultured keratinocytes (19).
We have previously shown in an animal model, the nude mouse with grafted human skin, that human IgG could be found in the skin grafts after parenteral injection of human anti-Ro (SSA) serum (3). Antibody binding was augmented somewhat by prior exposure of the grafts to ultraviolet light, a finding consistent with previous studies in cultured keratinocytes (19) and with the clinical observation that SCLE and NLE patients with anti-Ro (SSA) autoantibodies frequently are photosensitive $(1,20)$. It was hypothesized that the antibody binding observed in the animal model (3) was due to anti-Ro (SSA) antibodies, since IgG in other sera without anti-Ro (SSA) did not bind the human skin graft. In those experiments, however, the evidence that antibody binding was due to anti-Ro (SSA) was indirect. Also, even if the antibody binding were due to anti-Ro (SSA), the possibility remained that anti-Ro (SSA) antibodies were binding in the skin simply because of a possible affinity of anti-Ro (SSA) antibodies for mouse Ig.

In the present experiments we demonstrated by using affinity-purified antibodies and serum preabsorbed with purified Ro (SSA) antigen that anti-Ro (SSA) antibodies do indeed bind to the human skin. By repeating the anti-Ro (SSA) sera injections in grafted SCID mice, we showed that anti-Ro (SSA) antibody binding occurs even in the absence of mouse Ig and therefore cannot be explained by anti-Ig activity.

It seems likely that the antibody deposition observed represents in situ binding of anti-Ro (SSA) antibodies to Ro (SSA) antigen that is present in the skin, rather than a nonspecific deposit of circulating Ro (SSA)-anti-Ro (SSA) immune complexes. For one thing, affinity-purified antibodies were used in some experiments, so that immune complexes were not preformed before injection. After injection, it was unlikely that immune complexes would form in the circulation because of the lack of availability of antigen that would bind the human antibodies. The sera used did not contain antibodies that bound mouse antigens, and the amount of circulating human Ro (SSA) antigen contributed by the human skin graft must be small. Further, antibody binding was observed in the human skin graft but not in immediately adjacent mouse skin. This indicates that the antibodies bound specifically a human antigen and argues against the possibility that there was a nonspecific deposit of preformed immune complexes.

Most descriptions of the immunofluorescent findings in the skin in lupus erythematosus have focused on the deposition of Ig under the basement membrane zone $(21,22)$. A granular deposition of Ig under the basement membrane zone is often considered a sine qua non for a positive immunofluorescence test for lupus erythematosus, referred to by many authors as a lupus band test. The specific immunofluorescence findings in SCLE and NLE lesions have generally not been detailed, and the expected presence or absence of epidermal staining in these diseases cannot be fully assessed by examining previous reports. In our animal model it is striking that the most common immunofluorescence finding is IgG deposition in the epidermis rather than under the basement membrane zone. Although this pattern of deposition is different from that generally described in lupus erythematosus, it is nevertheless identical to that which we have seen in five of five SCLE and NLE skin biopsies examined by direct immunofluorescence. Skin biopsies from three of these patients are shown in Fig. 2. As Fig. 3 shows, epidermal staining is not an artifact produced during tissue sectioning. SCLE and NLE are clinically distin- 

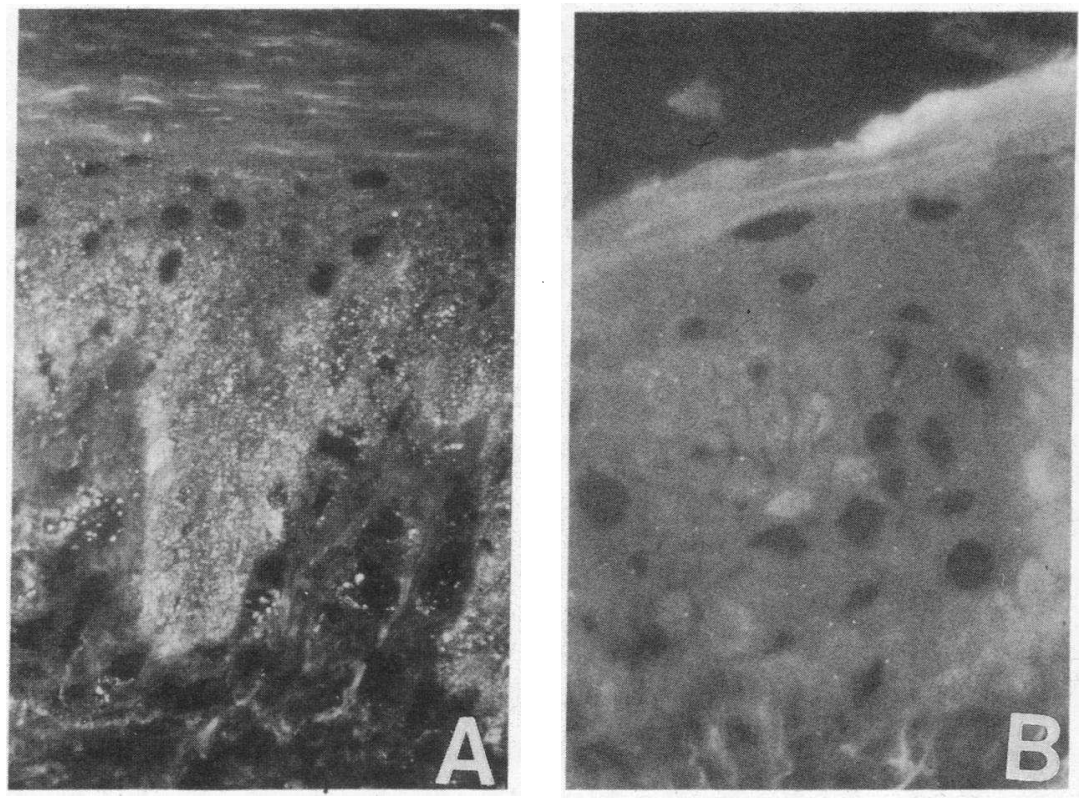

Figure 4. The effect of preabsorption of anti-Ro (SSA) serum with purified Ro (SSA) antigen. Nude mice were grafted with human skin, then injected either with anti-Ro (SSA) serum from patient 2 or with the same serum that was preabsorbed with Ro (SSA) antigen. Direct immunofluorescence examination for human IgG in the skin graft is shown. (A) Anti-Ro (SSA) serum was injected, and IgG deposition was seen in the epidermis. (Original magnification, $\times 630$.) (B) Anti-Ro (SSA) serum that was preabsorbed with purified Ro (SSA) antigen was injected. IgG deposition is virtually undetectable. (Original magnification, $\times 400$.)

guishable from discoid lupus (DLE) and skin lesions of SLE $(23,24)$, and SCLE can be distinguished histologically from DLE (25). In addition, the majority of SCLE and NLE patients have anti-Ro (SSA) antibodies, which is not the case with DLE and SLE. It seems likely that the distinctive immunofluorescence pattern we have observed in the human skin grafts and SCLE lesions is the result of specific binding of anti-Ro (SSA) antibodies in the skin.

SCLE is the form of cutaneous lupus erythematosus in adults that most closely resembles the skin lesions of NLE, which is why patient 1 was chosen for this study. Presumably the same maternal antibodies have produced indistinguishable skin lesions in both mother and offspring. This data shows that the purified anti-Ro (SSA) produced the same Ig pattern in the human skin graft as found in the lesional skin of patient 1 and her infant.

Many additional factors must also play a role before a rash can be appreciated. Some anti-Ro (SSA)-positive patients develop cutaneous lesions other than SCLE, and many do not develop skin lesions at all. Further, although the skin lesions developed by infants with NLE are very similar from patient to patient, infants with NLE are most frequently born to mothers who have no skin lesions (2). A few are born to mothers who have skin lesions that are clearly different from SCLE, such as the lesions of leukocytoclastic vasculitis (2). Work in this skin graft model to the present shows that all sera with Ro (SSA) precipitin activity, regardless of the clinical circumstances, bind antigens in the skin graft. No comprehensive study of the cutaneous deposition of IgG in patients and normal individuals with anti-Ro (SSA) has been done. Even if it can be assumed that Ig deposition is a general finding, there must be important factors beyond the Ig present in serum that vary from individual to individual and determine whether and which kind of skin lesions will appear.

Though the findings presented here support the potential importance of anti-Ro (SSA) in certain types of cutaneous lupus, they do not address the possible roles of other autoantibodies in SCLE and NLE. In fact, it seems likely that in some instances anti-La (SSB) or anti- $U_{1}$ RNP may contribute to
NLE. Cutaneous NLE has been noted in at least one patient who had anti-La (SSB) but not apparently anti-Ro (SSA) (26), and in two anti- $U_{1} R N P$-positive infants who did not have anti-Ro (SSA) antibodies as measured by a sensitive solid phase assay (27). It is of interest that anti-La (SSB) and anti$\mathrm{U}_{1} \mathrm{RNP}$ antibodies, like anti-Ro (SSA) antibodies, have also been shown to bind to viable cultured human keratinocytes $(18,28)$

Our results demonstrate that anti-Ro (SSA) autoantibodies, the autoantibodies most consistently found in SCLE and NLE, can bind specifically to the skin, particularly to the epidermis. The pattern of binding seen is identical to that we have observed in SCLE and NLE skin lesions. These findings establish that anti-Ro (SSA) antibodies bind to Ro (SSA) or a crossreacting antigen in the skin and may be directly implicated in the disease process producing subacute cutaneous lupus and cutaneous neonatal lupus.

\section{Acknowledgments}

We are grateful to Dr. Melvin Bosma for allowing us to use the SCID mice in these experiments, Marty Sanner for his technical assistance, Dr. Thomas J. Gargan III for providing tissues, and Dr. Richard Hyde for his suggestions and criticisms.

This study was supported in part by National Institutes of Health grants AR-01487, AR-26427, AM-34159, AI-24717, AM-31133, and AI-21568, a Clinical Research Center of the Arthritis Foundation, the Veterans Administration, NATO, and grants 5-507 and 1-1109 from the March of Dimes Birth Defects Foundation. Dr. Harley is an Investigator of the Arthritis Foundation.

\section{References}

1. Sontheimer, R. D., P. J. Maddison, M. Reichlin, R. E. Jordon, P. Stastny, and J. N. Gilliam. 1982. Serologic and HLA associations in subacute cutaneous lupus erythematosus, a clinical subset of lupus erythematosus. Ann. Intern. Med. 97:664-671.

2. McCune, A. B., W. L. Weston, and L. A. Lee. 1987. Maternal and fetal outcome in neonatal lupus erythematosus. Ann. Intern. Med. 106:518-523. 
3. Lee, L. A., W. L. Weston, G. G. Krueger, M. Emam, M. Reichlin, J. O. Stevens, S. K. Surbrugg, A. Vasil, and D. A. Norris. 1986. An animal model of antibody binding in cutaneous lupus. Arthritis Rheum. 29:782-788.

4. Harley, J. B., H. Yamagata, and M. Reichlin. 1984. Anti-La/SSB antibody is present in some normal sera and is coincident with antiRo/SSA precipitins in systemic lupus erythematosus. $J$. Rheumatol. 11:309-314

5. Mamula, M. J., O. F. Fox, and J. B. Harley. 1986. Cross-reactivity of Ro/SSA and immunoglobulin G. J. Exp. Med. 86:1889-1901.

6. Gaither, K. K., O. F. Fox, H. Yamagata, M. J. Mamula, M. Reichlin, and J. B. Harley. 1987. Implications of anti-Ro/Sjogren's syndrome A antigen autoantibody in normal sera for autoimmunity. $J$. Clin. Invest. 79:841-846.

7. Gaither, K. K., and J. B. Harley. 1985. Affinity purification and immunoassay of anti-Ro/SSA. Protides Biol. Fluids Proc. Colloq. 33:413-416.

8. Tan, E. M., A. S. Cohen, J. F. Fries, A. T. Masi, D. J. McShane, N. F. Rothfield, J. G. Schaller, N. Talal, and R. J. Winchester. 1982. The 1982 revised criteria for the classification of systemic lupus erythematosus. Arthritis Rheum. 25:1271-1277.

9. Lee, L. A., P. J. Lillis, K. A. Fritz, J. C. Huff, D. A. Norris, and W. L. Weston. 1983. Neonatal lupus syndrome in successive pregnancies. J. Am. Acad. Dermatol. 9:401-406.

10. Farr, R. 1971. Ammonium sulfate precipitation of soluble antigen-antibody complexes. 1. Determination of antigen binding capacity. Methods Immunol. Immunochem. 3:66-73.

11. Aarden, L. A., E. R. deGroot, and T. E. W. Feltkamp. 1975. Immunology of DNA. III. Crithidia luciliae, a simple substrate for the determination of anti-dsDNA with immunofluorescence technique. Ann. NY Acad. Sci. 254:505-514.

12. Yamagata, H., J. B. Harley, and M. Reichlin. 1984. Molecular properties of the Ro/SSA antigen and enzyme-linked immunosorbent assay for quantitation of antibody. J. Clin. Invest. 74:625-633.

13. Krueger, G. G., and M. Emam. 1984. Biology of Langerhans cells: analysis by experiments to deplete Langerhans cells from human skin. J. Invest. Dermatol. 82:613-617.

14. Huff, J. C., W. L. Weston, and K. D. Wanda. 1982. Enhancement of specific immunofluorescent findings with use of a para-phenylenediamine mounting buffer. J. Invest. Dermatol. 78:449-450.

15. Jordon, R. E. 1985. Lupus band test: clinical applications. Clinics in Dermatology. 3:113-122.
16. Bosma, G. C., R. P. Custer, and M. J. Bosma. 1983. A severe combined immunodeficiency mutation in the mouse. Nature (Lond.). 301:527-530.

17. Lee, L. A., C. E. Harmon, J. C. Huff, D. A. Norris, and W. L. Weston. 1985. SSA (Ro) antigen expression in human fetal tissues and in neonatal and adult skin. J. Invest. Dermatol. 85:143-146.

18. Jones, S. K., S. Coulter, C. Harmon, D. A. Norris, M. Rosandich, and L. A. Lee. 1988. Ro/SSA antigen in human epidermis. Br. J. Dermatol. 118:363-367.

19. LeFeber, W. P., D. A. Norris, S. R. Ryan, J. C. Huff, L. A. Lee, M. Kubo, S. T. Boyce, B. L. Kotzin, and W. L. Weston. 1984. Ultraviolet light induces binding of antibodies to selected nuclear antigens on cultured human keratinocytes. J. Clin. Invest. 74:1545-1551.

20. Weston, W. L., C. Harmon, C. Peebles, D. Manchester, H. L. Franco, J. C. Huff, and D. A. Norris. 1982. A serologic marker for neonatal lupus erythematosus. Br. J. Dermatol. 107:377-382.

21. Burnham, T. K., T. R. Neblett, and G. Fine. 1963. The application of the fluorescent antibody technique to the investigation of lupus erythematosus and various dermatoses. J. Invest. Dermatol. 41:451-456.

22. Harrist, T. J., and M. C. Mihm. 1980 . The specificity and clinical usefulness of the lupus band test. Arthritis Rheum. 23:479490.

23. Gilliam, J. N., and R. D. Sontheimer. 1981. Distinctive cutaneous subsets in the spectrum of lupus erythematosus. J. Am. Acad. Dermatol. 4:471-475.

24. Lee, L. A., and W. L. Weston. 1986. Lupus erythematosus in childhood. In Dermatologic Clinics, Vol. 4. S. Hurwitz, editor. W. B. Saunders Company, Philadelphia. 151-160.

25. Bangert, J. L., R. G. Freeman, R. D. Sontheimer, and J. N. Gilliam. 1984. Subacute cutaneous lupus erythematosus and discoid lupus erythematosus. Arch. Dermatol. 120:332-337.

26. Lee, L. A., C. Lekan, and S. Coulter. 1987. Characterization of autoantibodies associated with neonatal lupus. J. Invest. Dermatol. 88:502. (Abstr.)

27. Provost, T. T., R. Watson, W. R. Gammon, M. Radowsky, J. B. Harley, and M. Reichlin. 1987. Neonatal lupus syndrome associated with $U_{1}$ RNP (nRNP) antibodies. $N$. Engl. J. Med. 316:1135-1138.

28. Furukawa, F., M. B. Lyons, S. Coulter, L. A. Lee, and D. A. Norris. 1988. Ultraviolet light induction of Ro and La antigens on human keratinocytes: a crucial component of photosensitive cutaneous lupus erythematosus? Clin. Res. 36:249A. (Abstr.) 